\title{
A Lagrangian strategy for in situ sampling the physical-biological coupling at fine scale : the PROTEVSMED-SWOT 2018 cruise
}

Roxane Tzortzis $^{1}$, Andrea M. Doglioli ${ }^{1}$, Stéphanie Barrillon ${ }^{1}$, Anne A. Petrenko ${ }^{1}$, Francesco d'Ovidio ${ }^{2}$, Lloyd Izard ${ }^{1}$, Melilotus Thyssen ${ }^{1}$, Ananda Pascual ${ }^{3}$, Frédéric Cyr $^{4}$, Franck Dumas ${ }^{5}$, and Gérald Gregori ${ }^{1}$

- $\quad{ }^{1}$ Aix Marseille Univ., Université de Toulon, CNRS, IRD, MIO, UM 110, 13288, Marseille, France

- ${ }^{2}$ Sorbonne Université, CNRS, IRD, MNHN, Laboratoire d'Océanographie et du Climat : Expérimentations et Approches Numériques (LOCEAN-IPSL), Paris, France

- $\quad{ }^{3}$ IMEDEA (CSIC-UIB), Instituto Mediterraneo de Estudios Avanzados, Esporles, Spain

- $\quad{ }^{4}$ Northwest Atlantic Fisheries Centre, Fisheries and Oceans, St. John's, NL, Canada

- ${ }^{5}$ SHOM, Service Hydrographique et Océanographique de la Marine, 13 rue de Chatellier, CS592803, 29228 Brest, CEDEX 2, France

The term "fine scales" is generally used to refer to the ocean processes occuring on horizontal scales smaller than 10 $\mathrm{km}$ and characterized by a short lifetime (days/weeks). Fine scales have been predominantly studied with numerical simulations and satellite observations which have highlighted their significant role on biological processes. Indeed, their short time scale is the same as a lot of important processes in phytoplankton dynamics. Model simulations have shown that fine scales such as fronts and filaments strongly influence the distribution of phytoplankton species. Nowadays, the combination of in situ measurements, satellite observations and model simulations is a necessity to better understand these mechanisms. However these processes are particularly challenging to sample in situ because of their size and their ephemeral nature.

The PROTEVSMED-SWOT cruise was performed in the Western Mediterranean Sea, in the southern region of the Balearic Islands, onboard BHO Beautemps-Beaupré, between April $30^{\text {th }}$ and May $14^{\text {th }}, 2018$. In order to study the influence of fine scales on the distribution of phytoplankton species, a satellite-based adaptive Lagrangian sampling strategy has been deployed in order to i) identify a fine scale structure of interest, ii) sample it at high spatial resolution the phytoplankton community, and iii) follow the evolution of this structure and the related distribution of phytoplankton. The SPASSO software package uses satellite altimetry, SST and surface Chl a concentration data to generate and provide near-real time daily maps of the dynamical and biogeochemical structures present in the area. The sampling strategy was defined in order to cross a frontal zone separating different types of water. Multidisciplinary in situ sensors (hull-mounted ADCP, a Seasoar towed fish and an automated flow cytometer installed on the seawater supply of the Thermosalinograph) were used to sample at high spatial resolution physical and biological variables. A particular attention was put in adapting the temporal sampling in different water masses to the biological time scales in order to reconstruct the phytoplankton diurnal cycle.

Such a strategy was successful in sampling two different water masses separated by a narrow front and characterized by different aboundances of several phytoplankton species and functional groups. Consequently, our results highlight the role of the front on the physical and biological coupling confirming previous modelling and remote-sensing studies.

The new generation of altimetric satellite, SWOT, will provide a 2D sea surface height at an unprecedented resolution and it will be a unique opportunity to better observe fine scale structures in the global ocean. Our methodology paves the way to future in situ experiments that are planned in 2022 during the SWOT fast-sampling phase, few months after its launch.

How to cite: Tzortzis, R., Doglioli, A. M., Barrillon, S., Petrenko, A. A., d'Ovidio, F., Izard, L., Thyssen, M., Pascual, A., Cyr, F., Dumas, F., and Gregori, G.: A Lagrangian strategy for in situ sampling the physical-biological coupling at fine scale : the PROTEVSMED-SWOT 2018 cruise, EGU General Assembly 2020, Online, 4-8 May 2020, EGU2020-7357, https://doi.org/10.5194/egusphere-egu2020-7357, 2020 